\title{
8-OHdG in Cerebrospinal Fluid as a Marker of Oxidative Stress in Various Neurodegenerative Diseases
}

\author{
K. Gmitterováa, b U. Heinemann ${ }^{a} \quad$ J. Gawinecka ${ }^{a} \quad$ D. Varges ${ }^{a} \quad$ B. Ciesielczyk ${ }^{a}$ \\ P. Valkovic ${ }^{b} \quad$ J. Benetin ${ }^{b} \quad$ I. Zerr ${ }^{a}$

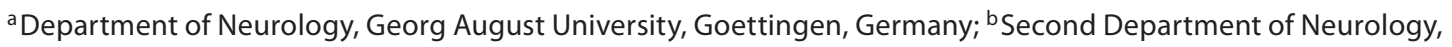 \\ Comenius University, Bratislava, Slovakia
}

Key Words

Cerebrospinal fluid $\cdot 8-\mathrm{OHdG} \cdot$ Parkinson's disease $\cdot$

Oxidative stress

\begin{abstract}
Background: The 8-hydroxy-2 deoxyguanosine (8-OHdG) is a product of nucleoside oxidation of DNA and a reliable marker of oxidative stress markers. Increased levels of oxidative stress have been reported in the cerebrospinal fluid (CSF) of patients with various neurodegenerative disorders. Objective: In search of a biochemical indicator of Parkinson's disease (PD), we analyzed the levels 8-OHdG in the CSF of 99 patients, using ELISA to assess the differences between various neurodegenerative disorders. Results: Statistically significant higher CSF levels ( $p=0.022)$ of $8-O H d G$ in nondemented PD patients as compared to the control group were observed. No differences between CSF 8-OHdG levels and age at the time of lumbar puncture, presence or severity of dementia, or gender were found. Conclusions: 8-OHdG levels could be potentially useful in the neurochemically supported diagnosis of PD.

Copyright $\odot 2009$ S. Karger AG, Basel
\end{abstract}

\section{Introduction}

There is increasing evidence that oxidative damage is involved in the pathogenesis of various neurodegenerative disorders, including amyotrophic lateral sclerosis [1, 2], Huntington's disease [3], Parkinson's disease (PD) [4, 5] and Alzheimer's disease (AD) [6-8].

The nucleic acid can be damaged by reactive oxygen free radicals, which are generated in cellular metabolic pathways and by exposure to environmental oxidants. Highly reactive oxygen species (specifically the hydroxyl radical) attack DNA, leading to the hydroxylation of DNA and RNA [9-12]. Among the multiple products of nucleoside oxidation, 8-hydroxy-2-deoxyguanosine (8-OHdG) and 8 -hydroxyguanosine $(8-\mathrm{OHG})$ are 2 of the most prominent and best characterized $[10,11]$. Brain tissue shows a higher susceptibility to oxidative stress due to free radicals, which is caused by insufficient content of antioxidants, the considerable content of polyunsaturated fatty acid side chains in the cell membrane lipid layer, and by its high oxygen consumption rate [13-15]. Moreover, ageing is associated with increased production of free radicals, and promoters of oxidative DNA damage have been found to be increased in the cerebral tissue of healthy aged subjects [16] as well as patients with $\mathrm{AD}[6,17]$.

Department of Neurology, University Medical School Georg August University of Goettingen

Robert-Koch-Str. 40, DE-37075 Goettingen (Germany)

Tel. +4955139 6636, Fax +49551 39 7020, E-Mail epicjd@med.uni-goettingen.de 
Several studies have found increased levels of 8-OHdG in the damaged neuronal populations of postmortem brains in patients with $\mathrm{AD}[6,7]$, Huntington's disease [3] and amyotrophic lateral sclerosis [1], as well as increased 8 -OHG in the substantia nigra of PD patients $[18,19]$. In addition to this brain-associated damage, high levels of 8-OHdG have also been demonstrated in peripheral tissues in AD [20], suggesting a systemic increase in oxidative nucleic acid damage in neurodegenerative diseases. In PD, oxidative stress has been suggested to play a pivotal role in disease pathogenesis $[15,21]$.

Similar RNA oxidation in the neuronal cytoplasm has also been observed in the brains of patients with Lewy body dementia (LBD) [22], Creutzfeldt-Jakob disease [23] and subacute sclerosing panencephalitis [24]. Further studies have demonstrated that neuronal RNA oxidation is followed by detection of the oxyform of nucleoside in the AD brain $[25,26]$. Significantly higher levels of 8 OHG have been identified not only in the brain, but also in the CSF of patients with $\mathrm{AD}$ and $\mathrm{PD}[4,27]$ as well as in serum of PD patients [4] compared to age-matched controls, which indicates that 8-OHG might be a useful biomarker of these diseases.

In this study, we analyzed cerebrospinal fluid (CSF) 8-OHdG levels in various neurodegenerative disorders using an ELISA, and investigated factors that might modify these.

\section{Patients and Methods}

The study comprised 97 patients with various neurodegenerative disorders which were registered from April 2005 to August 2007 at the Department of Neurology, Georg August University (Goettingen, Germany), and the Department of Neurology, Comenius University (Bratislava, Slovakia), with a full clinical data set and CSF samples available.

Subject consent was obtained in agreement with the Declaration of Helsinki and the local ethics committee, and informed consent from all patients or their caregivers was provided (and is available).

\section{Diagnoses}

Alzheimer's Disease. Eighteen patients with AD were investigated due to suspicion of Creutzfeldt-Jakob disease, because of rapid progression, atypical course or young onset of the disease. The diagnoses were based on NINCDS-ADRDA (National Institute of Neurological and Communicative Disorders and Stroke/ Alzheimer's Disease and Related Disorders Association) criteria [28]. In the process of further analyses, their data were further stratified according to age at disease onset (younger or older than 65 years), disease duration (less or more than 6 months before the lumbar puncture was performed) and the severity of the dementia.
Dementia with Lewy Bodies. Eighteen patients fulfilled the criteria for probable LBD [29].

Parkinson's Disease. Forty-eight patients with a diagnosis of PD according to the UK Parkinson's Disease Society Brain Bank criteria $[29,30]$ were included in this study.

According to the McKeith criteria [29, 31], PD were patients further divided into a group without dementia (PD) to represent early stages of the disease and a group with dementia (PDD) mirroring advanced stages.

\section{Controls}

The control group comprised 13 non-demented patients (MMSE score ranging between 28 and 30 points) who underwent the lumbar puncture to exclude a structural neurological disorder. Their diagnoses were: depression $(n=6)$, schizophrenia $(n=$ $2)$, migraine $(n=2)$, transient global amnesia $(n=1)$, chronic fatigue syndrome $(n=1)$ and trigeminal neuralgia $(n=1)$.

\section{Data Analysis}

First, we analyzed the data by the type of diagnosis. Then, we grouped patients without cognitive impairment (PD patients and control group) as the non-dementia group, and the remaining patients (PDD, LBD and AD) as a dementia group.

Considering the potential influence of the severity of dementia on the 8-OHdG levels, we additionally defined the mild/moderate dementia (MMSE score: 20-27) and severe dementia groups.

Age at the time of sampling was categorized into 4 clinically meaningful groups of age, with patients younger than 60 years being the reference group. Regarding the disease duration up to the point when the lumbar puncture was performed, we divided our patients into 3 groups: duration less than 6 months, duration of 6-24 months and duration longer than 24 months after the primary diagnosis was estimated.

Analysis of CSF for 8-OHdG. CSF samples were obtained by lumbar puncture. The routine investigation of the CSF did not reveal any abnormalities with respect to the cell count and proteins. Blood-contaminated samples were excluded from analysis because contamination of this type can lead to abnormal results. CSF samples were centrifuged immediately after lumbar puncture at 2,000 $\mathrm{g}$ for $10 \mathrm{~min}$. CSF supernatant was rapidly frozen, and stored at $-80^{\circ} \mathrm{C}$ until the measurement was performed.

All samples were measured concomitantly using the same capture ELISA kit. A commercially available 8-OHdG capture kit was used (8-OHdG Check high sensitive, IBL Transatlantic, Toronto, Canada). The standard measurement range was $0.125-10 \mathrm{ng} / \mathrm{ml}$. Quantification was attained by comparing absorbance intensity to a standard curve.

Statistical Analysis. Descriptive statistics were calculated for every group. Significances were tested by SigmaStat version 3.1 (Systat Software, Point Richmond, Calif., USA) using Student's t test or the Mann-Whitney rank-sum test; for more than 2 groups, the Kruskal-Wallis test was used. A value of $p<0.05$ was considered significant. The correlation between the levels of $8-\mathrm{OHdG}$ and clinical or demographic features were analyzed by Pearson's correlation coefficient. 
Table 1. Clinical and demographic characteristics of the patients $(n=97)$

\begin{tabular}{|c|c|c|c|c|c|}
\hline & $\mathrm{AD}$ & LBD & $\mathrm{PD}$ & PDD & Controls \\
\hline $\mathrm{n}$ & 18 & 18 & 27 & 21 & 13 \\
\hline Age at onset, years & $63(47-79)$ & $73.5(56-84)$ & $59(41-83)$ & $67(57-77)$ & $62(51-86)$ \\
\hline Age at the time of lumbar puncture, years & $65(48-82)$ & $76(56-84)$ & $61.3(47-83)$ & $67.8(57-78)$ & $62(51-86)$ \\
\hline Time from diagnosis to lumbar puncture, years & $1.4(0.3-5.2)$ & $1.6(0.1-4.4)$ & $2.3(0.1-17)$ & $7.2(2.8-26)$ & \\
\hline Time from PD to dementia, years & & & & $6.8(3-23.7)$ & \\
\hline MMSE score ${ }^{1}$ & $\begin{array}{l}21(13-25) \\
\mathrm{n}=15\end{array}$ & $\begin{array}{l}13(8-18) \\
\mathrm{n}=9\end{array}$ & $\begin{array}{l}29(27-30) \\
\mathrm{n}=26\end{array}$ & $\begin{array}{l}20(14-25) \\
\mathrm{n}=10\end{array}$ & $\begin{array}{l}30(28-30) \\
\mathrm{n}=13\end{array}$ \\
\hline $\begin{array}{l}\text { Psychiatric investigations, } \mathrm{n} \\
\text { (mild-moderate/severe dementia) }\end{array}$ & $9(5 / 4)$ & $15(5 / 10)$ & 2 & $8(4 / 4)$ & 5 \\
\hline
\end{tabular}

Data presented as number of patients or median values with ranges in parentheses. When results from the both MMSE and psychiatric investigation were available, we preferred the results from the psychiatric evaluation.

${ }^{1}$ Sabbagh et al. [41].

\section{Results}

\section{Patient Characteristics}

Measurements of 8 -OHdG proteins by ELISA were performed on 97 patients with various neurodegenerative disorders (AD, LBD, PD, PDD) and healthy controls (46 women, 51 men, ratio 0.90 ). Clinical and demographic data are displayed in table 1.

\section{8-OHdG Analysis in CSF}

The levels of CSF 8-OHdG varied between different neurodegenerative disorders (fig. 1). In the $\mathrm{AD}$ group, the median 8-OHdG level was $0.89 \mathrm{ng} / \mathrm{ml}(0.125-1.85 \mathrm{ng} /$ $\mathrm{ml})$. No significant differences were found with regard to age at the disease onset, disease duration or severity of dementia in the $\mathrm{AD}$ group. In the LBD group, a median of $0.81 \mathrm{ng} / \mathrm{ml}$ and a mean $0.83 \pm 0.25 \mathrm{ng} / \mathrm{ml}(0.24-1.25$ $\mathrm{ng} / \mathrm{ml}$ ) were calculated. The whole PD group showed a tendency towards higher CSF levels (median $0.97 \mathrm{ng} / \mathrm{ml}$ and mean $0.98 \pm 0.41 \mathrm{ng} / \mathrm{ml}$ ) as compared to other investigated groups.

In the next step, we evaluated the data by the presence or absence of dementia. In the PDD group, the median 8 -OHdG level was $0.95 \mathrm{ng} / \mathrm{ml}$ (mean $0.90 \pm 0.38 \mathrm{ng} / \mathrm{ml}$, range $0.21-1.73 \mathrm{ng} / \mathrm{ml}$ ); in $\mathrm{PD}$, the median was calculated to be $0.98 \mathrm{ng} / \mathrm{ml}$ (mean $1.0 \pm 0.45 \mathrm{ng} / \mathrm{ml}$, range $0.2-2.0$ $\mathrm{ng} / \mathrm{ml}$ ). Thus, in both groups, the median levels were very close.

In comparison to these results, we observed the lowest 8-OHdG CSF levels in the control group, where the median reached the value of $0.69 \mathrm{ng} / \mathrm{ml}$ (mean $0.71 \pm 0.29$ $\mathrm{ng} / \mathrm{ml}$, range $0.14-1.31 \mathrm{ng} / \mathrm{ml}$ ). Whereas levels of all PD patients tended to be higher than in controls, only those without dementia were significantly different $(p=0.03)$.

Although no significant difference was observed between demented and nondemented patients irrespective of the diagnosis, there was a negative trend with dementia severity. The median 8-OHdG CSF level was higher (0.9 $\mathrm{ng} / \mathrm{ml}$ ) in mild/moderate cognitive decline as compared to severe cognitive impairment $(0.8 \mathrm{ng} / \mathrm{ml})$, but did not reach a significant level for the whole population studied here. There was a negative correlation $(\mathrm{r}=-0.59, \mathrm{p}=$ 0.034 ) between 8-OHdG CSF levels and decline in cognitive functions (evaluated with MMSE) in demented PD patients. However, further statistical analyses regarding the severity of cognitive impairment in PDD group were not significant.

There was no significant difference in any dementia group (AD, LBD, PDD) between mild/moderate dementia in comparison to severe dementia. There was no influence of age at the time of sampling or gender on 8-OHdG CSF levels in all subgroups. Results are displayed in table 2 and figures 1 and 2 .

\section{Discussion}

Oxidative damage may play an important role in the pathogenesis of several neurodegenerative diseases, and growing evidence points out the involvement of free radicals in mediating neuronal death in these disorders [1-8, 32]. Thus, markers of oxidative damage reflecting the disease and potentially the disease stage and severity may be detectable in body fluids of affected patients. In this work, 


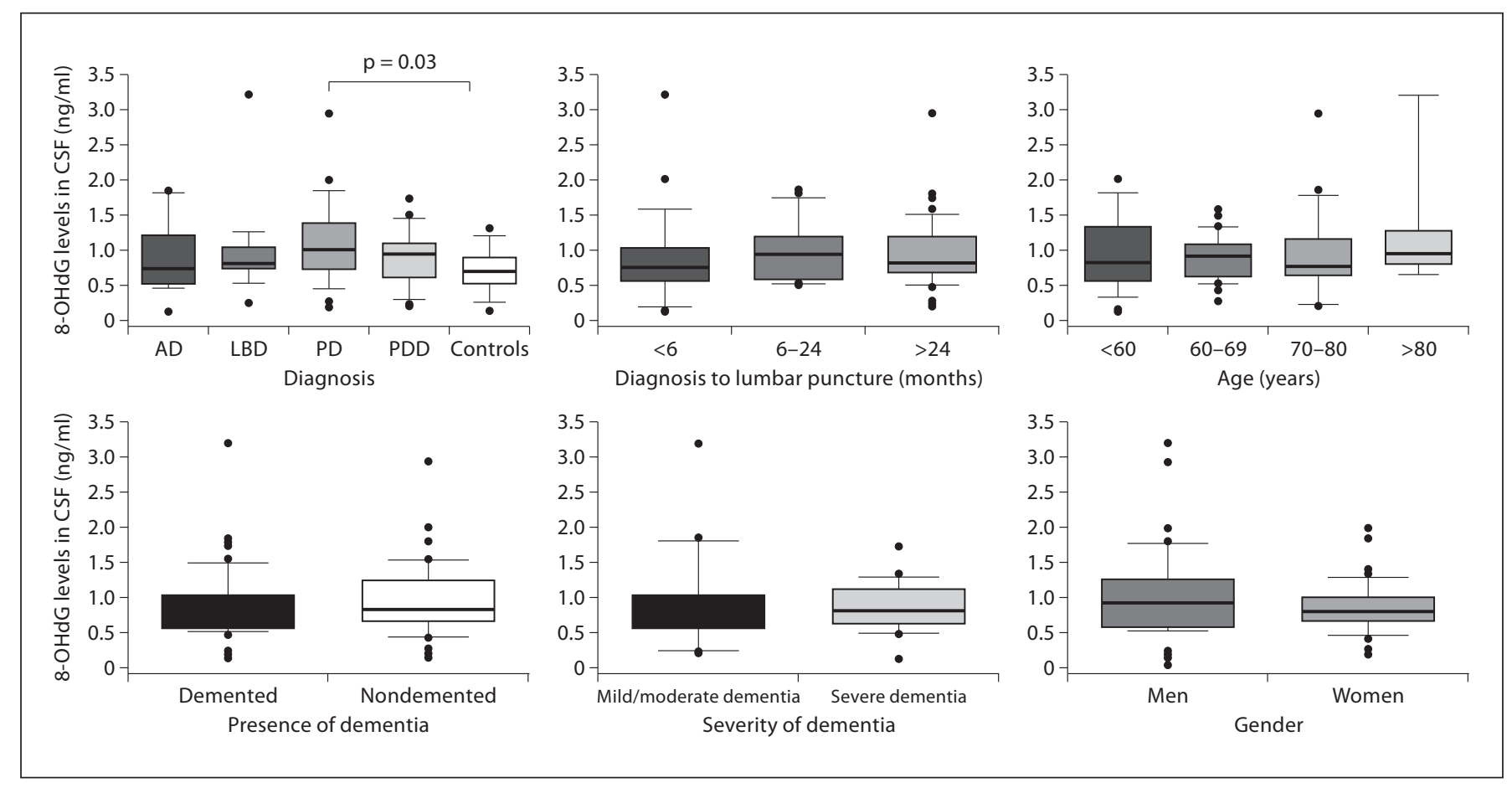

Fig. 1. 8-OHdG levels in CSF.

Fig. 2. Correlation between MMSE score

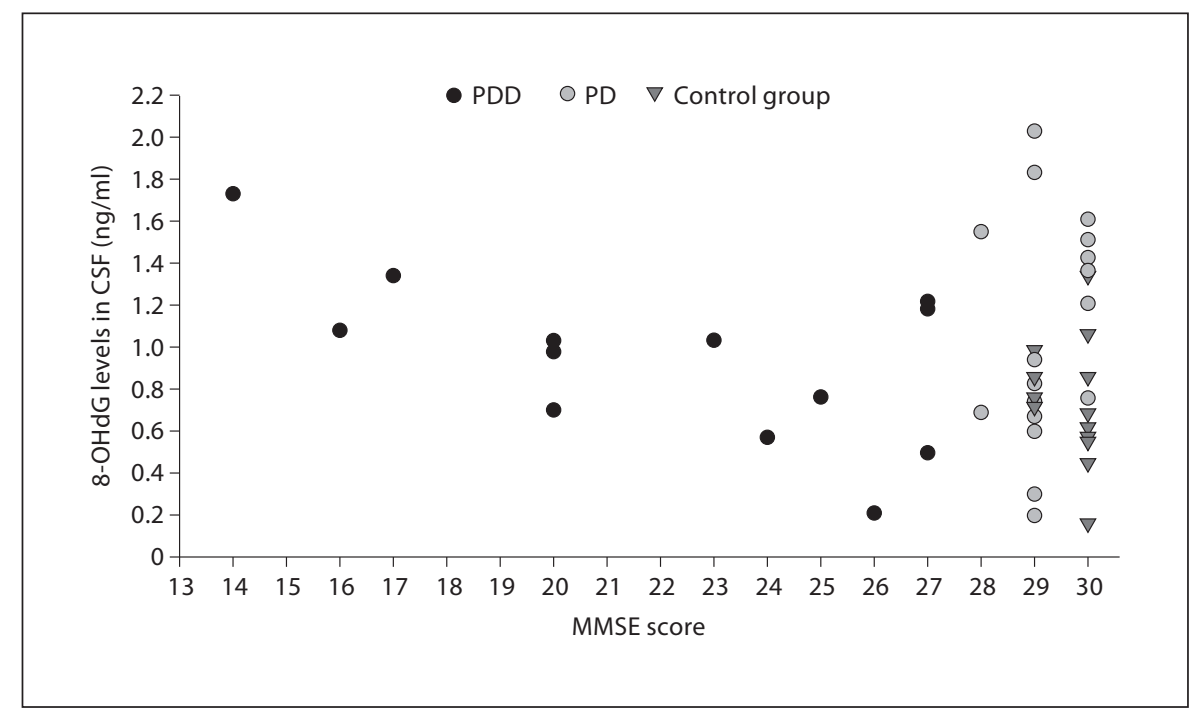
and 8-OHdG levels in CSF.

we evaluated 8-OHdG levels as a marker of oxidative stress in the CSF of 97 patients to assess the differences between various neurodegenerative disorders. The most strongly elevated 8-OHdG CSF levels were observed in nondemented PD patients, which were significantly higher when compared to the controls.
This is in accordance with the study performed by Abe et al. [27] measuring the concentrations of 8-OHG in the CSF and serum of patients with PD, which were approximately 3-fold higher in PD patients than in controls. Although we could not confirm this fully, our results pointed to the same direction. According to the aforemen- 
Table 2. Levels of CSF 8-OHdG in various neurodegenerative diseases and controls

\begin{tabular}{lc}
\hline Variable & 8 -OHdG levels (range) \\
\hline Diagnosis & \\
$\quad$ AD & $0.89 \pm 0.47(0.125-1.85)$ \\
LBD & $0.83 \pm 0.25(0.24-1.25)$ \\
PD & $1.0 \pm 0.45(0.2-2.0)$ \\
PDD & $0.90 \pm 0.38(0.21-1.7)$ \\
Controls & $0.71 \pm 0.29(0.14-1.3)$ \\
Time from diagnosis to lumbar puncture \\
$\quad<6$ months & $0.80 \pm 0.44(0.125-2.0)$ \\
$\quad 6-24$ months & $0.98 \pm 0.40(0.5-1.9)$ \\
$>24$ months & $0.90 \pm 0.36(0.2-1.8)$ \\
Age, years & \\
$<60$ & $0.95 \pm 0.5(0.125-2.0)$ \\
$\quad 60-69$ & $0.90 \pm 0.3(0.2-1.6)$ \\
$70-79$ & $0.83 \pm 0.4(0.2-1.8)$ \\
$>80$ & $0.96 \pm 0.2(0.7-1.3)$ \\
Presence of dementia & \\
Demented & $0.90 \pm 0.38(0.125-1.8)$ \\
Nondemented & $0.87 \pm 0.42(0.14-2.0)$ \\
Severity of dementia & \\
Mild/moderate & $0.90 \pm 0.4(0.2-1.9)$ \\
Severe & $0.86 \pm 0.34(0.125-1.7)$ \\
Gender & \\
Men & $0.95 \pm 0.45(0.125-2.0)$ \\
Women & $0.86 \pm 0.35(0.2-2.0)$ \\
\hline
\end{tabular}

tioned study, the concentration of 8-OHG in CSF shows a significant decrease with the duration of disease.

Although slightly different in the design, our findings point towards the same direction: we demonstrated a decreasing trend for 8-OHdG with disease stage, and PD patients in advanced stages of the disease associated with dementia showed lower 8-OHdG levels as compared with $\mathrm{PD}$ patients without cognitive decline.

Since many PD patients develop dementia, efforts have been made to determine whether the correlation between functional and cognitive decline is seen in PD. Although the MMSE often fails to detect very early cognitive decline in PD patients, it correlates positively with disease severity as determined by the functional motor scales (motor UPDRS) [33].

The stratification of our data was done according to the variables that have shown important associations in previous studies. In a cohort of 88 patients with sporadic $\mathrm{PD}$, a significant association between neuropathological stage and cognitive status as determined by MMSE (a linear trend) was reported, indicating that the risk of developing dementia increases with disease progression [34,
35]. In the same study, Hoehn-Yahr correlated PD stage with MMSE score; this was not observed for MMSE and disease duration, age at disease onset or age at death. The decrease in MMSE scores in advanced PD stages indicates that the risk of dementia increases with disease progression. With respect to these considerations, one would expect higher levels of oxidative damage products in advanced disease stages, and consequently also in patients with PD and dementia. Our findings are partially in accordance with this hypothesis. Although levels of oxidative damage are higher in all PD patients than controls, the differences were more obvious in nondemented PD patients as compared to the PD group with dementia. However, there was an increase in 8-OHdG CSF levels with lower MMSE score in the PDD group. No significant result was found when the severity of dementia within this group was considered. The trend of $8-\mathrm{OHdG}$ levels to increase with severity of PD dementia suggests the important role of oxidative stress, presumably with other mechanisms, in the disease progression.

These findings support our hypothesis that increased oxidative DNA/RNA damage may play an important role in the early stages of the neurodegenerative pathways in PD. However, during disease progression, the neurodegenerative process is more complex and other mechanisms are more prominent. Therefore, $8-\mathrm{OHdG}$ might be a promising 'early-stage marker' of the disease.

Concomitant medication in PD may have a potential influence on neurochemical findings. This has been studied in 66 PD patients using metabolomics. Medication-free patients as well as PD patients receiving dopaminergic therapies were analyzed. The authors demonstrated that the differences between controls and PD subjects were not related to drug effects. Corresponding with our findings, 8-OHdG levels in PD patients were significantly increased as compared to controls [36]. According to these results, we did not stratify our patients according to dopaminergic treatment.

The results obtained in our study are in accordance with a study comparing patients with PD and multiple system atrophy [4]. Significantly higher serum levels, as well as CSF levels of 8-OHdG/8-OHG in PD patients, were observed. Unfortunately, clinically meaningful features, such as presence and severity of dementia, were not taken into account. In our study, 8-OHdG levels were higher in PD patients than in other groups, but no significant difference was observed when the data were stratified by cognitive status.

Several studies have reported that the levels of 8OHdG/8-OHG in the substantia nigra, caudate nucleus 
and other brain regions were higher in PD than in agematched controls, which might explain the abnormal findings in the CSF $[5,18]$. The main source of increased serum 8-OHdG/8-OHG in PD has still not been sufficiently elucidated. Although it is well known that dopaminergic neurons are the most vulnerable cells in PD, various studies have suggested other neuronal cells, skeletal muscle cells [37], lymphocytes [38] and visceral organs [39] are also involved in the disease process, and might therefore be possible sources of increased 8-OHdG.

This is the first study to investigate 8-OHdG CSF levels in a group of LBD patients in order to assess its potential role in the differentiation of PDD and LBD as 2 distinct clinical entities; this distinction remains controversial. In our study, there were no significant differences between these groups. Only a limited number of studies have dealt with oxidative damage in both conditions. The extent and distribution of 8-OHG in dopaminergic neurons (cytoplasmic 8-OHG immunoreactivity in substantia nigra) in PD and LBD patients were similar and differed from age-matched controls [40], but the number of positive neurons was significantly less in LBD than in PD patients, suggesting the diminished likelihood of 8-OHG being released into the CSF. This is in accordance with our findings detecting lower 8-OHdG CSF levels in LBD than in PD patients. In another study [22], neurons with marked immunoreaction of 8-hydroxyguanosine were widely distributed in the hippocampal region and temporal neocortex of LBD patients, which is similar to previous findings in the AD brain [41]. In accordance with this, there were no differences in 8-OHdG levels between these subgroups in our study.

The detection of a biomarker in PD represents one of the major challenges for the future because of the importance of the early identification of affected individuals, definition of subgroups and development of neuroprotective treatment strategies. Based on the current results and findings by other authors, we conclude that estimation of 8-OHdG in CSF might be useful in the diagnosing of PD mainly in early stages.

Prospective neuropathological and clinical studies have to follow up this research, in order to establish and verify the potential of $8-\mathrm{OHdG}$ as a marker for diagnosis, prognosis and monitoring of $\mathrm{PD}$.

\section{Acknowledgments}

Special thanks to Monica Bodemer for her technical assistance. We also thank Maja Schneider Dominco and Jolanthe Ehrlich for editorial assistance and helpful comments. This study was supported by the European Commission (SP5A-CT-2007044438, Prionscreen).

\section{References}

1 Ferrante RJ, Browne SE, Shinobu LA, Bowling AC, Baik MJ, MacGarvey U, Kowall NW, Brown RHJ, Beal MF: Evidence of increased oxidative damage in both sporadic and familial amyotrophic lateral sclerosis. J Neurochem 1997;69:2064-2074.

-2 Bogdanov M, Brown RH, Matson W, Smart R, Hayden D, O'Donnell H, Beal MF, Cudkowicz M: Increased oxidative damage to DNA in ALS patients. Free Rad Biol Med 2000;29: 652-658.

-3 Browne SE, Bowling AC, MacGarvey U, Baik MJ, Berger SC, Muqit MM, Bird ED, Beal MF: Oxidative damage and metabolic dysfunction in Huntington's disease: selective vulnerability of the basal ganglia. Ann Neurol 1997;41:646-653.

4 Kikuchi A, Takeda A, Onodera H, Kimpara T, Hisanaga K, Sato N, Nunomura A, Castellani RJ, Perry G, Smith MA, Itoyama Y: Systemic increase of oxidative nucleic acid damage in Parkinson's disease and multiple system atrophy. Neurobiol Dis 2002;9:244248 .
5 Sanchez-Ramos JR, Overvik E, Ames BN: A marker of oxyradical-mediated DNA damage (8-hydroxy-2-deoxyguanosine) is increased in nigra-striatum of Parkinson's disease brain. Neurodegeneration 1994;3: 197-204.

-6 Mecocci P, MacGarvey U, Beal F: Oxidative damage to mitochondrial DNA is increased in Alzheimer's disease. Ann Neurol 1994;36: $747-751$.

-7 Nunomura A, Perry G, Alieu G, Hirai K, Takedu A, Balraj EK, Jones PK, Ghanbari H, Wataya T, Shimohama S, Chiba S, Atwood CS, Petersen RB, Smith MA: Oxidative damage is the earliest event in Alzheimer disease. J Neuropathol Exp Neurol 2001;60:759-767.

-8 Lovell MA, Markesbery WR: Ratio of 8-Hydroxyguanine in intact DNA to free 8-hydroxyguanine is increased in Alzheimer disease ventricular cerebrospinal fluid. Arch Neurol 2001;58:392-396.

-9 Adelman R, Saul RL, Ames BN: Oxidative damage to DNA: relation to species metabolic rate and life span. Proc Natl Acad Sci USA 1988;85:2706-2708
10 Fiala ES, Conaway CC, Mathis JE: Oxidative DNA and RNA damage in the livers of Sprague-Dawley rats treated with the hepatocarcinogen 2-nitropropane. Cancer Res 1989;49:5518-5522.

11 Wamer WG, Wei RR: In vitro photooxidation of nucleic acids by ultraviolet A radiation. Photochem Photobiol 1997;65:506563.

12 Hofer T, Badouard C, Bajak E, Ravanat JL, Mattsson A, Cotgreave IA: Hydrogen peroxide causes greater oxidation in cellular RNA than in DNA. Biol Chem 2005;386:333-337.

13 Christen Y: Oxidative stress and Alzheimer disease. Am J Clin Nutr 2000;71:6215-6295.

14 Beal MF, Lang AE, Ludolph A: Neurodegenerative Diseases. Cambridge, Cambridge University Press, 2005.

15 Lin MT, Beal MF: Mitochondrial dysfunction and oxidative stress in neurodegenerative diseases. Nature 2006;443:787-795.

16 Mecocci P, MacGarvey U, Kaufmann AE: Oxidative damage to mitochondrial DNA shows marked age-dependent increases in human brain. Ann Neurol 1993;34:609616. 
17 Gabbita SP, Lovell MA, Markesbery WR: Increased nuclear DNA oxidation in the brain in Alzheimer's disease. J Neurochem 1998; 71:2034-2040.

-18 Alam ZI, Jenner A, Daniel SE, Lees AJ, Cairns N, Marsden CD, Jenner P, Halliwell $\mathrm{B}$ : Oxidative DNA damage in the parkinsonian brain: an apparent selective increase in 8-hydroxyguanine levels in substantia nigra. J Neurochem 1997;69:1196-1203.

19 Zhang J, Perry G, Smith MA, Robertson D, Olson SJ, Graham DG, Montine TJ: Parkinson's disease is associated with oxidative damage to cytoplasmic DNA and RNA in substantia nigra neurons. Am J Pathol 1999; 154:1423-1429.

20 Mecocci P, Polidori MC, Ingegni T, Cherubini A, Chionne F, Cecchetti R, Senin U: Oxidative damage to DNA in lymphocytes from AD patients. Neurology 1998;51:1014-1017.

-21 Jenner P, Dexter DT, Sian J, Schapira AH, Marsden CD: Oxidative stress as a cause of nigral cell death in Parkinson's disease and incidental Lewy body disease: The Royal Kings and Queens Parkinson's Disease Research Group. Ann Neurol 1992;32:S82S87.

22 Nunomura A, Chiba S, Kosaka K: Neuronal RNA oxidation is a prominent feature of dementia with Lewy bodies. Neuroreport 2002; 13:2035-2039.

-23 Guentchev M, Siedlak SL, Jarlus C, Tagliavini F, Castellani RJ, Perry G, Smith MA, Budka H: Oxidative damage to nucleic acids in human prion disease. Neurobiol Dis 2002; 9:275-281.

24 Hayashi M, Arai N, Satoh J: Neurodegenerative mechanisms in subacute sclerosing panencephalitis. J Child Neurol 2002;17:725281.

25 Shan X, Lin CLG: Quantification of oxidized RNAs in Alzheimer's disease. Neurobiol Aging 2006;27:657-662.
26 Honda K, Smith MA, Zhu X, Baus D, Merrick WC, Tartakoff AM, Hattier T, Harris PL, Siedlak SL, Fujioka H, Liu Q, Moreira PI, Miller FP, Nunomura A, Shimohama S, Perry G: Ribosomal RNA in Alzheimer disease is oxidized by bound redox-active iron. J Biol Chem 2005;280:20978-20986.

$\checkmark 27$ Abe T, Isobe C, Murata T, Sato C, Tohgi H Alteration of 8-hydroxyguanosine concentrations in the cerebrospinal fluid and serum from patients with Parkinson's disease. Neurosci Lett 2003;336:105-108.

28 McKhann G, Drachmann D, Folstein M, Katzmann R, Price D, Stadlan EM: Clinical diagnosis of Alzheimer's disease: Report of the NINCDS-ADRDA Work Group under the auspices of the Department of Health and Human Services Task Force of Alzheimer's disease. Neurology 1984;34:934-944.

29 McKeith IG, Galasko D, Kosaka K, Perry EK, Dickson DW, Hansen LA, Salmon DP, Lowe J, Mirra SS, Byrne EJ, Lennox G, Quinn NP, Edwardson JA, Ince PG, Bergeron C, Burns A, Miller BL, Lovestone S, Collerton D, Jansen EN, Ballard C, de Vos RA, Wilcock GK, Jellinger KA, Perry RH: Consensus guidelines for the clinical and pathologic diagnosis of dementia with Lewy bodies (DLB): report of the consortium on DLB international workshop. Neurology 1996;47:1113-1124.

30 Huges AJ, Daniel SE, Blankson S, Lees AJ: A clinicopathologic study of 100 cases of Parkinson's disease. Arch Neurol 1993;50:140148.

31 Emre M, Aarsland D, Brown R, Burn DJ, Duyckaerts C, Mizuno Y, Broe GA, Cummings J, Dickson D, Gauthier S, Goldman J, Goetz C, Korczyn A, Lees A, Levy R, Litvan I, McKeith IG, Olanow W, Poewe W, Quinn N, Sampaio C, Tolosa E, Dubois B: Clinical diagnostic criteria for dementia associated with Parkinson's disease. Mov Disord 2007; 22:1689-1707.

32 Praticò D, Reilly M, Lawson JA, FitzGerald GA: Novel indices of oxidant stress in cardiovascular disease: specific analysis of F2. isoprostanes. Agents Actions Suppl 1997;48: 25-41.
33 Sabbagh MN, Silverberg N, Bircea S, Majeed B, Samant S, Caviness JN, Reisberg B, Adler $\mathrm{CH}$ : Is the functional decline of Parkinson's disease similar to the functional decline of Alzheimer's disease? Parkinsonism Relat Disord 2005;11:311-315.

-34 Braak H, Rüb U, Jansen Steur EN, Del Tredici K, de Vos RA: Cognitive status correlates with neuropathologic stage in Parkinson disease. Neurology 2005;64:1404-1410.

>35 Braak H, Rüb U, Del Tredici K: Cognitive status correlates with neuropathologic stage in Parkinson's disease. J Neurol Sci 2006; 248:255-258

>36 Bogdanov M, Matson WR, Wang L, Matson T, Saunders-Pullmann S, Bressman SS, Beal F: Metabolomic profiling to develop blood biomarkers for Parkinson's disease. Brain 2008;131:389-396.

37 Blin O, Desnuelle C, Rascol O, Borg M, Peyro Saint Paul H, Azulay JP, Bille F, Figarella D, Coulom F, Pellissier JF, Montastruc JL, Chatel M, Serratrice G: Mitochondrial respiratory failure in skeletal muscle from patients with Parkinson's disease and multiple system atrophy. J Neurol Sci 1994;125:95101.

38 Barroso N, Campos Y, Huertas R, Esteban J, Molina JA, Alonso A, Gutierrez-Rivas E, Arenas J: Respiratory chain enzyme activities in lymphocytes from untreated patients with Parkinson disease. Clin Chem 1993;39: 667-669.

>39 Wakabayashi K, Takahashi H, Ohama E, Takeda S, Ikuta F: Lewy bodies in the visceral autonomic nervous system in Parkinson's disease. Adv Neurol 1993;60:609-612.

40 Zhang R, Pinson A, Samuni A: Both hydroxylamine and nitroxide protect cardiomyocytes from oxidative stress. Free Rad Biol Med 1998;24:66-75.

-41 Nunomura A, Perry G, Pappolla MA: RNA oxidation is a prominent feature of vulnerable neurons in Alzheimer's disease. J Neurosci 1999;19:1959-1964. 